\title{
A study on the fatigue strength characteristics of ship structural steel with gusset welds
}

\author{
Sung-Jo Park and Hyun-Woo Lee \\ Mechanical Engineering, Pusan National University, Busan, Korea
}

\begin{abstract}
This study aims to assess fatigue property by the static overload and average load in the fillet welded joints which is on the ship structural steel having gusset welds. To this end, a small specimen was made, to which the same welding condition for the actual ship structure was applied, to perform fatigue tests. In this study, a method to simply assess changes in welding residual stress according to different static overload was suggested. By measuring actual strain at the weld toe, the weld stress concentration factor and property which is determined by recrystallization in the process of welding were estimated to investigate the relation between overload and fatigue strength.
\end{abstract}

KEY WORDS: Fatigue strength; Overload; Gusset weld; Residual stress.

\section{INTRODUCTION}

Generally welded parts of a structure have residual stress equivalent to the yield stress of the parent material. In this residual stress condition, the stress ratio has little effect on the fatigue strength under a constant amplitude loading (Gurney, 1979). Therefore in the development stage of a welded structure under variable amplitude loading, the fatigue strength has been estimated by calculating accumulated damage during the life of use from the distribution of stress amplitude density by taking advantage of S-N curve which is derived from a small test specimen with weld residual stress. And the same process has been applied for the fatigue strength assessment of a welded structure of a vessel.

But unlike general land or marine welded structures, the welded structures of vessels are more affected by the static load from cargo than the variable load from wave (Maddox, 1991; Gurney, 1979). The initial weld residual stress could be reduced considerably by the hydraulic pressure test after shipbuilding causing tensile stress at weld connections (Kim, 1997). Therefore it is recommended taking into consideration those factors mentioned above when designing and building vessels and welded structures.

In this thesis, among various weld types found in vessel structures, the gusset type weld is investigated for the redistribution of the residual stress according to the magnitude $\left(0.5 \sigma_{y s}, 0.85 \sigma_{y s}\right)$ of initial static load and the effect of the mean stress $(0.5$ $\sigma_{y s}, 0.85 \sigma_{y s}$ ) to the fatigue strength by the weight of cargo. And the relation between overload and fatigue strength is investigated by estimating the material properties and the weld stress concentration factor after the recrystalization by measuring the real strains at weld toes.

\section{THEORIORICAL BACKGROUND}

\section{Relation between stress and strain}

Generally the residual stress without external force is in the balanced state for an arbitrary cross-section. Weld zone with

Corresponding author: Sung-Jo Park

e-mail:fatigue@pusan.ac.kr 
tensile residual stress of yield stress tend to result in local plastic deformation under small external tensile force. Therefore when the external load is removed, the magnitude and the distribution of tensile residual stress are different from before. At weld zone, as shown in Fig. 1, when external loads is applied as A-B-C, the magnitude of decreasing tensile residual stress is proportional to the local plastic strain $\left({ }^{\varepsilon_{p}}\right)$ (Lee and Cho, 1995; Kim, 1992; Park, Han and Han, 1997; AWS, 1987; Kim, 1989).

General equation of stress and strain can be obtained relation Eq. (1) from the results of tensile tests (Bannantine, Comer and Handrock, 1990).

$$
\varepsilon=\frac{\sigma}{E}+\left(\frac{\sigma}{K}\right)^{\frac{1}{n}}
$$

The applied stress is $\sigma$ and $\varepsilon$ is the applied strain, $K$ is strength coefficient, $n$ is strength exponent.

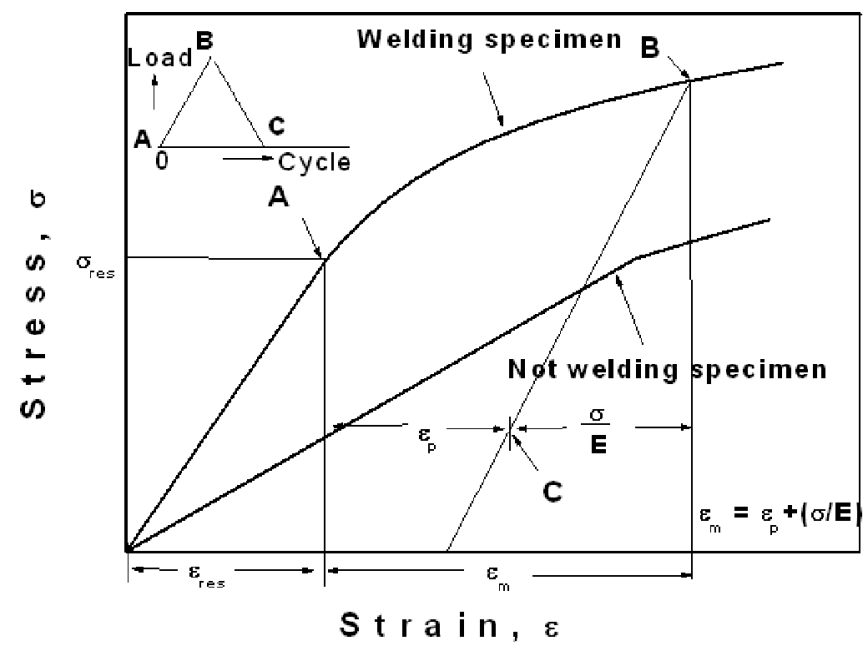

Fig. 1 Stress and strain response of welding specimen.

\section{TEST RESULT AND CONSIDERATION}

\section{Test specimen}

Material that was used in the study is Mild Steel 'grade A' for the ship structure. On the edge of the specimen, a gusset is welded with shape and size as shown in Fig. 2. Table 1 and Table 2 show its welding conditions and chemical composition and mechanical properties of the material.

Table 1 Welding conditions.

\begin{tabular}{|c|c|c|c|}
\hline Current & Voltage & Speed & Method \\
\hline $220 \mathrm{~A}$ & $26 \mathrm{~V}$ & $50 \mathrm{~cm} / \mathrm{min}$ & Semi-automatic $\mathrm{CO}_{2}$ \\
\hline
\end{tabular}

Table 2 Chemical composition and mechanical properties of the material.

\begin{tabular}{|c|c|c|c|c|}
\hline \multirow{2}{*}{ Material } & $\mathrm{C}$ & $\mathrm{Si}$ & $\mathrm{Mn}$ & Ceq \\
\hline \multirow{3}{*}{ Mild Steel } & $0.13 \sim 0.2$ & $0.1 \sim 0.2$ & $0.51 \sim 0.79$ & $0.25 \sim 0.29$ \\
\cline { 2 - 5 } & \multicolumn{2}{|c|}{ Yield strength $(M P a)$} & $\begin{array}{c}\text { Ultimate Strength } \\
(M P a)\end{array}$ & $\begin{array}{c}\text { Elongation } \\
(\%)\end{array}$ \\
\cline { 2 - 5 } & Design & Actual & $427 \sim 457$ & $26 \sim 34$ \\
\hline
\end{tabular}




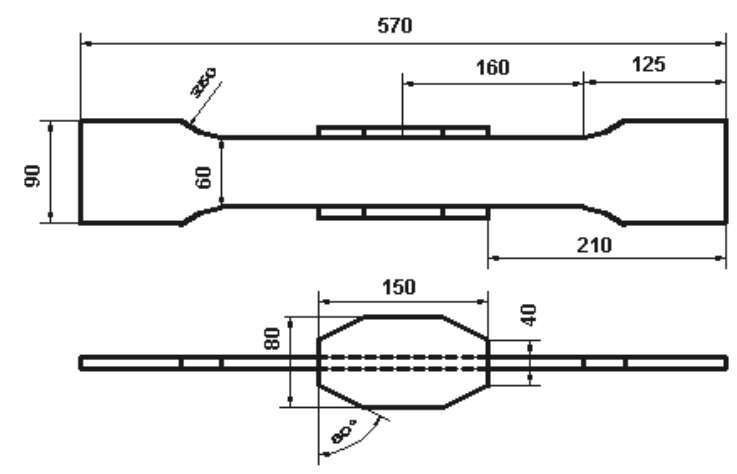

Fig. 2 The geometry of the weldment specimen with gussets on the edge of plate (unit: $\mathrm{mm}$ ).

\section{Measuring residual stress and result}

The fatigue strength at the weld joint is determined by the structural stress concentration according to shapes along with the size and distribution of residual stress stemmed from the welding heat at the welded toe. Accordingly the residual stress at the weld toe is measured based on the three load conditions in Table 3. The measurement of residual stress conforms to the Strain Gauge Sectioning Method (S.G.S.M). As described in Fig. 3, 2-axises strain gages (KFG-1-120-D1-11, Kyowa Ltd., Jap.) are attached 2,12,22 $\mathrm{mm}$ in longitudinal direction and 5, 15 $\mathrm{mm}$ in width direction apart from weld toe. Strains are measured by Dynamic Strain Measurement System (PCD-200A, Kyowa Ltd., Jap). After measuring strains, force is applied and the specimen is cut into cubic pieces with 1 2mm gap around gages as shown in Fig. 5 to measure strains again and figure out the differences ( $\Delta \varepsilon_{x}, \Delta \varepsilon_{y}$ ) for the calculation of residual stress on surface defined as Eq. (2).

$$
\begin{gathered}
\sigma_{x}=\frac{E}{\left(1-v^{2}\right)}\left(\Delta \varepsilon_{x}+v \Delta \varepsilon_{y}\right) \\
\sigma_{y}=\frac{E}{\left(1-v^{2}\right)}\left(v \Delta \varepsilon_{x}+\Delta \varepsilon_{y}\right)
\end{gathered}
$$

Poisson's ratio $v$ is 0.3 which is the average from the simple tensile test. The residual stress is measured at four different points of the toe in the same specimen. In order to minimize the frictional heat by the cutter while measuring strain through S.G.S.M., compressed air is used to cool down and heat generated from the surface of the gauge is regularly checked. When it comes to welded specimen for the test, the residual stress to the length direction at the welded toe has almost the same value as the yield strength in the base material. The Condition 1 in the Table 3, which was found by S.G.S.M., showed the residual stress of maximum $288 \mathrm{MPa}$ (approx. $1.23 \sigma_{y s}$ ) at $2 \mathrm{~mm}$ from the welded toe (1) in Fig. 3) whereas $188 \mathrm{MPa}$ was found depending on locations in the same specimen. This is because the distribution of residual stress is different, and measured strain changes sensitively at the toe because of welding path, shape of weld bead, and cutting process. Based on these founding, it is considered that the measured residual stress appears large ranges. With overload of $0.5 \sigma_{y s}$ and $0.85 \sigma_{y s}$ in the Condition 2 and 3 , the measured residual stress displayed tensile residual stress of 209-239 $\mathrm{MPa}$ and 140-162 $\mathrm{MPa}$ respectively measured at (1) in Fig. 3. Fig. 5 and 6 illustrate arithmetical average of the residual stress calculated by S.G.S.M. excluding locations where gauges were broken. In case of As-weld in Fig. 4, the value was less than that of $0.5 \sigma_{y s}$, as the range of measured residual stress is large. But the maximum residual stress decreases with increasing overloads.

Table 3 Overload condition for the measurement of residual stress.

\begin{tabular}{|c|c|}
\hline Condition & Load Pattern \\
\hline 1 & As-welded \\
\hline 2 & $0.5 \sigma_{y s}$ over load \\
\hline 3 & $0.85 \sigma_{y s}$ over load \\
\hline
\end{tabular}




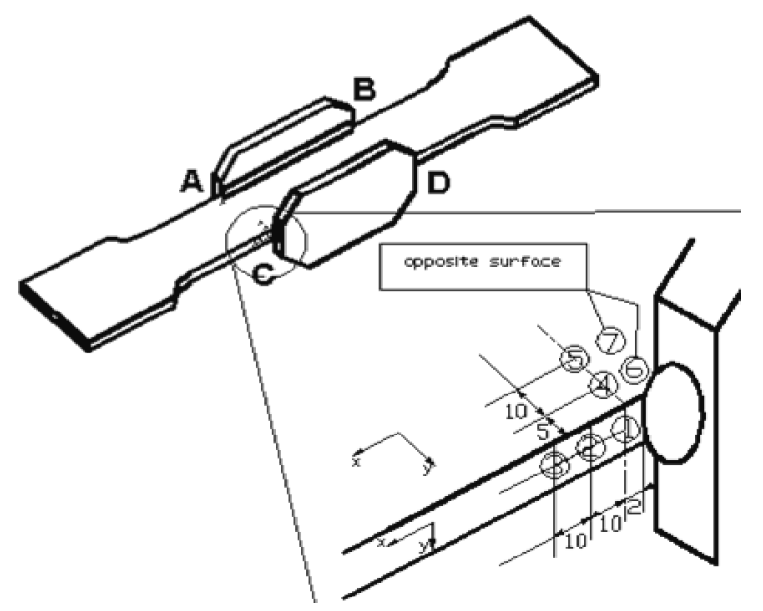

Fig. 3 Locations of attached strain gages for measurement of residual stress (unit: $\mathrm{mm}$ ).

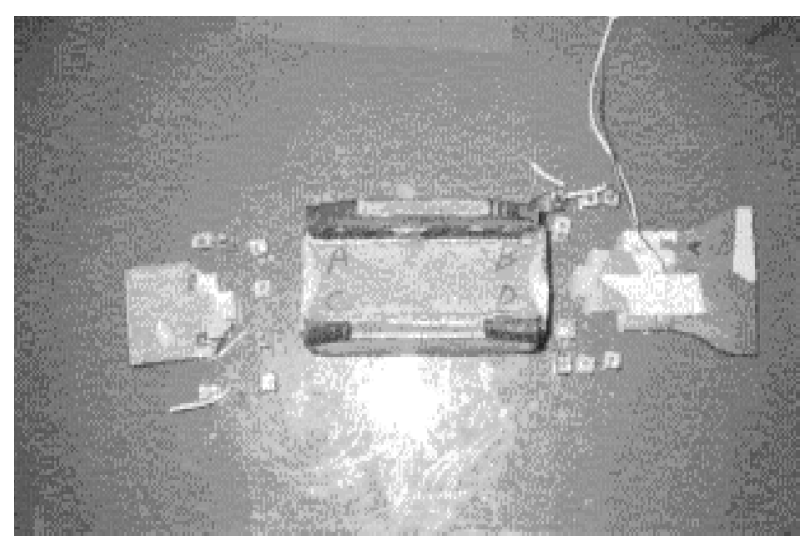

Fig. 4 A photograph of the cut specimen for measurement of residual stress by strain gage sectioning method (S.G.S.M.).

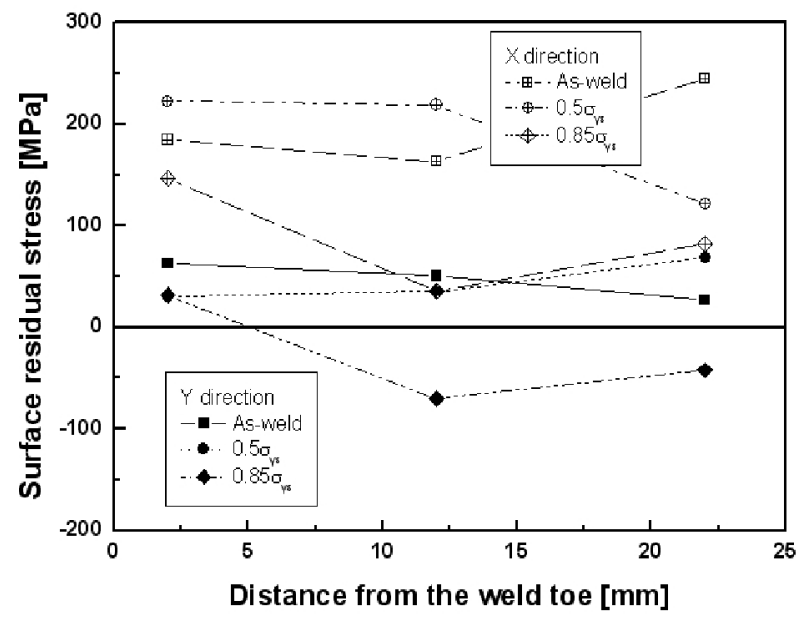

Fig. 5 Distribution of surface residual stress measured by S.G.S.M. (strain gage (1), (2), (3)).

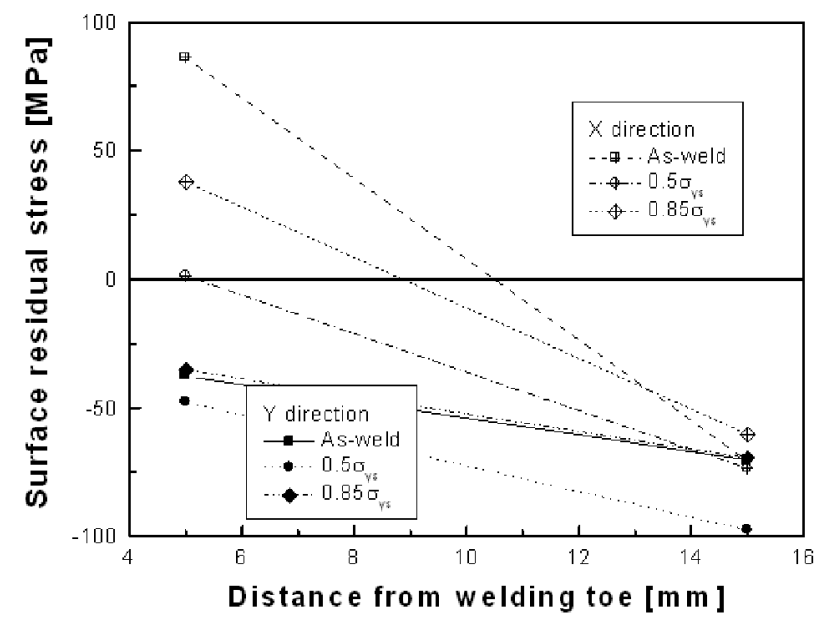

Fig. 6 Distribution of surface residual stress measured by S.G.S.M. (strain gage (4), (5), 6), (7)).

\section{Fatigue test result and consideration}

In an effort to access the redistribution of residual stress and fatigue life determined by the mean stress, fatigue tests were conducted under the five conditions in Table 4, and the test loading was set to meet $\frac{P_{\min }-P_{\text {mean }}}{P_{\max }-P_{\text {mean }}}=-1$. As Fig. 7 shows, for each 
condition, a fatigue test was performed on the same loading pattern. Also on each condition, minimum 15 speci-mens, which is recommendation of IIW (Internal Institute of Welding), were used to calculate stress and life curve. The fatigue strength is defined when the stress range exists in the cycle of $10^{5}-5 \times 10^{6}$. And the fatigue life is defined against the cycle number in the completely broken specimen. The test result was arranged by the least squares method.

Table 4 The load conditions of fatigue test.

\begin{tabular}{|c|c|c|c|}
\hline \multirow{2}{*}{ Condition } & \multicolumn{3}{|c|}{ Load Pattern } \\
\cline { 2 - 4 } & $P_{\text {ovl }}$ & $P_{\text {mean }}$ & $\frac{P_{\text {min }}-P_{\text {mean }}}{P_{\text {max }}-P_{\text {mean }}}$ \\
\hline 1 & 0 & 0 & -1 \\
\hline 2 & $0.5 \sigma_{y s}$ & 0 & -1 \\
\hline 3 & $0.85 \sigma_{y s}$ & 0 & -1 \\
\hline 4 & $0.85 \sigma_{y s}$ & $0.5 \sigma_{y s}$ & -1 \\
\hline 5 & $0.85 \sigma_{y s}$ & $0.5 \sigma_{y s}$ & -1 \\
\hline
\end{tabular}

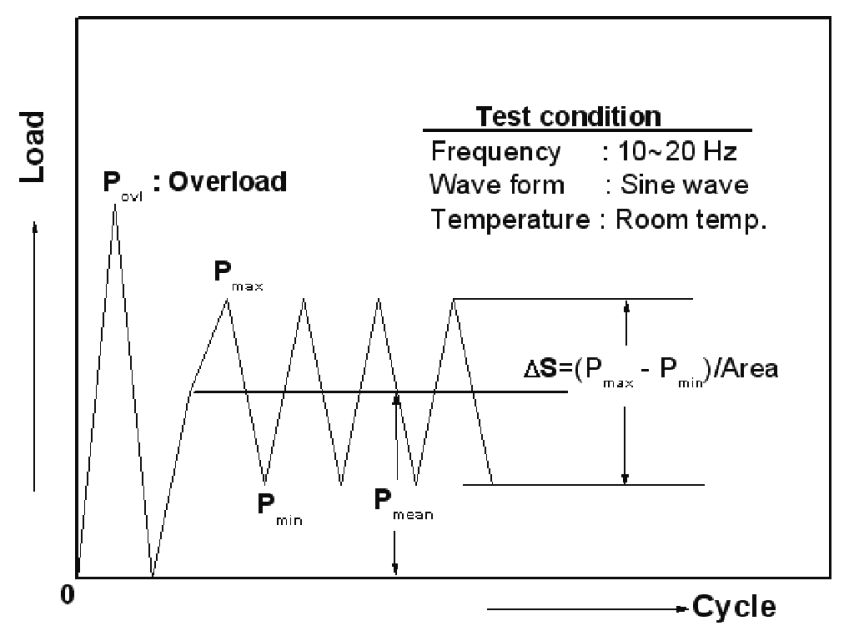

Fig. 7 Fatigue test loading pattern and condition.

\section{Effect of residual stress redistribution}

Test results based on the Condition 1, 2, and 3 in Table 4 are shown in Fig. 8 in order to assess the effect of fatigue strength as the residual stress is redistributed. As Fig. 8 illustrates, overload changes the fatigue strength and the fatigue strength increases with heavier overload. It is considered that applied overload released to the length direction from the weld toe and increased the fatigue life. Compared to the As-weld condition, changes in the fatigue strength on the high cycle range was bigger than on the low cycle range. In this vein, the fatigue strength receives more impact on the high cycle range which has less load amplitude.

\section{Effect of mean stress}

It has been generally known that the mean stress influences less on the weld metal. In order to assess the stress strength caused by the mean stress, the weld residual stress was minimized to $0.85 \sigma_{y s}$ and tests were carried out on the Condition 4 and 5 in Table 4. As Fig. 8 shows, the fatigue strength created big differences as the mean stress changes in comparison of the Condition 3, 4 and 5. With increasing the mean stress, the fatigue strength declines, which is typical, whereas the width of strength became narrow with higher mean stress. Decline in the fatigue strength due to the mean stress was bigger in the high cycle range. Because such effects from the mean stress were not fully relieved even with applying $0.85 \sigma_{y s}$ as overload, it is regarded that overlapped residual stress and stress amplitude produced extra changes in the residual stress and redistribution. 
For the fatigue strength produced by the mean stress and overload based on the yield stress in Fig 8, the mean stress (Condition 3, 4 and 5 in Table 4) has bigger impact on the fatigue life than the residual stress (Condition 1, 2 and 3 in Table 4). In particular, compared with the As-weld results, at the $10^{6}$ cycle, $0.5 \sigma_{y s}$ of the mean stress reduced the stress range by $50 \mathrm{MPa}$ at the fatigue stress $(\Delta S)$ and $0.85 \sigma_{y s}$ of the mean stress reduced the stress range by $55 \mathrm{MPa}$.

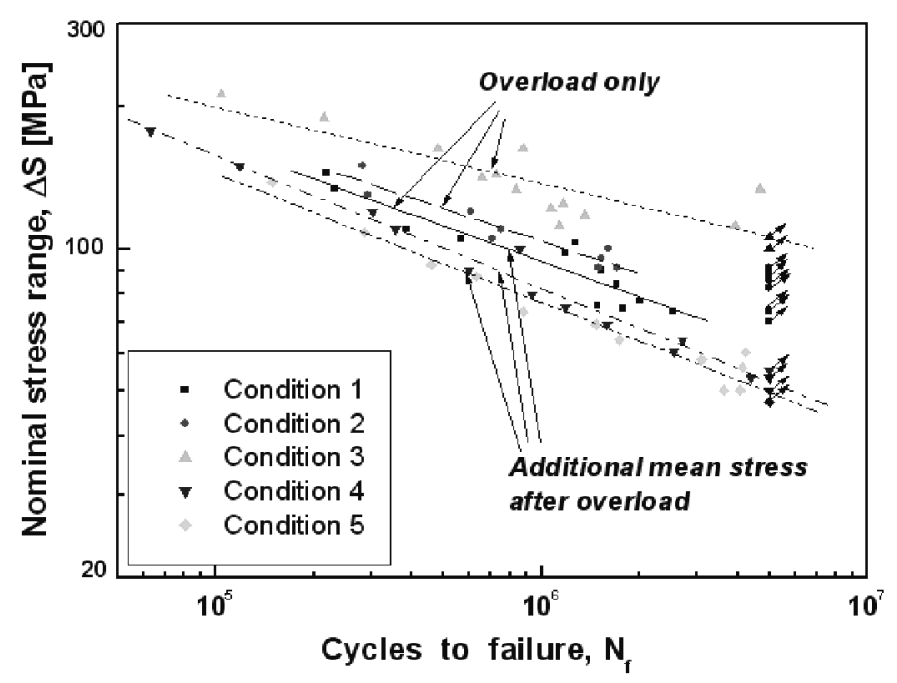

Fig. 8 The results of fatigue test according to overload and mean stress.

\section{Consideration of weld stress concentration factor and partial strain at toe}

In order to obtain the partial plastic strain and stress concentration factor at the toe of the specimen, where cracks initiate, as Fig. 9 shows, a strain gauge of $5 \mathrm{~mm}$ length is attached on the three different locations, [2], [3], and [4] that are $2 \mathrm{~mm}\left(\mathrm{~m}^{\prime}\right)$ from the toe. In this situation, load was increased by $5 \mathrm{kN}$ at a time and reduced to measure strain $\left(\varepsilon_{m}\right)$ and plastic strain $\left(\varepsilon_{p}\right)$. Because high tensile residual stress exists at this welded toe, large plastic strain occurs with a small amount of external load. As Fig. 10 illustrates, there are many differences even in the same material compared with the simple tensile test using non-weld specimen.

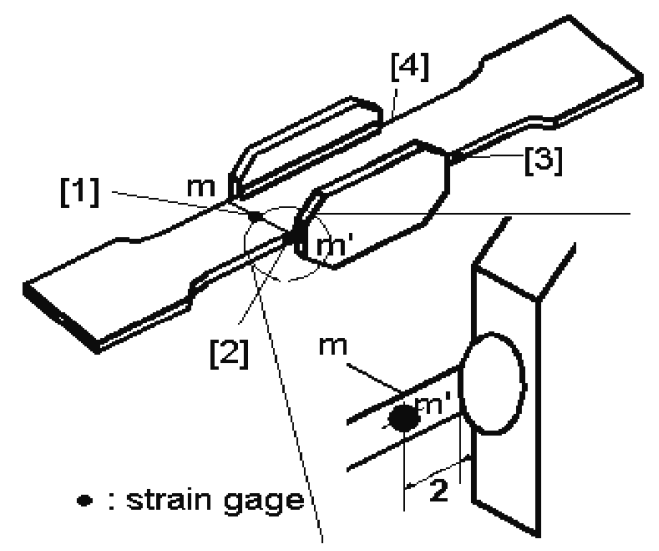

Fig. 9 Positions of attached strain gages for welding stress concentration factor.

As a result of measurement, the elastic behavior was found up until $70 \mathrm{kN}$. The welding stress concentration factor was calculated under $100 \mathrm{MPa}$ at which stress and strain change lineally. $K_{w c}$ was 0.85 at [1] and 1.66-1.68 at [2], [3] and [4] at which there was no big change.

The reason of the difference of weld stress concentration factor $\left(K_{w c}\right)$ between each toe is considered due to the variation of bead shape, flank angle and curvature radius. Additional influence from the change of elastic modulus and stiffening by recrystallization at weld toes due to local weld heat is also one of the reasons that could explain why small values are measured 
than the stress concentration factor of real geometric shape.

Compared to the simple tensile test, partial $\mathrm{E}$ at the weld toe increased by 1.04 times, 3.76 times for $K$ and 3.27 times for $n$. Therefore the wield stress concentration factor obtained from the test is one that considers both changes in tissues in the welding process and structural stress concentration.

\section{Relation between nominal stress due to weld concentration factor and relieved residual stress}

One of the most important factors in the assessment of fatigue strength at weld zone is the stress concentration by geometric difference and the magnitude of residual stress by local heat and constraints. Therefore the effect of stress concentration can be obtained from the stress-strain curve (Fig. 10). Using the average of plastic strain at position [2], [3] and [4], the relation with external force (or overload) can be defined as the Eq. (5).

And using the residual stress at weld toes (position (1) Fig. 3) obtained by S.G.S.M, the amount of released residual stress $\left(\sigma_{r r s}\right)$ to overloads can be calculated and the relation with plastic strain is defined as the Eq. (6). For the plastic strains measured during load release, the external force and the amount of release of residual stress can be related linearly in doublelogarithmic graph as depicted in Fig. 11.

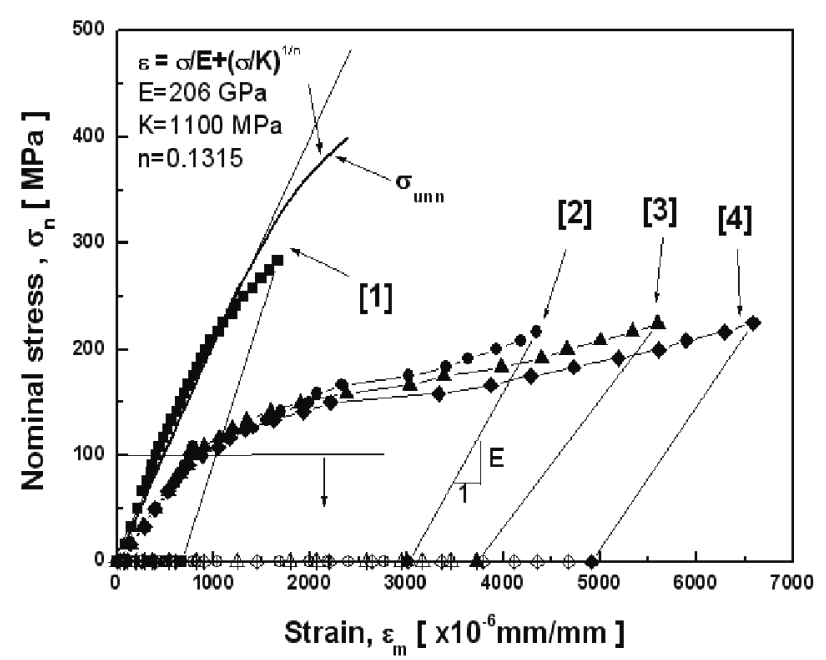

Fig. 10 The relation between nominal stress and measured strain at the weld toe (at [2], [3], [4]).

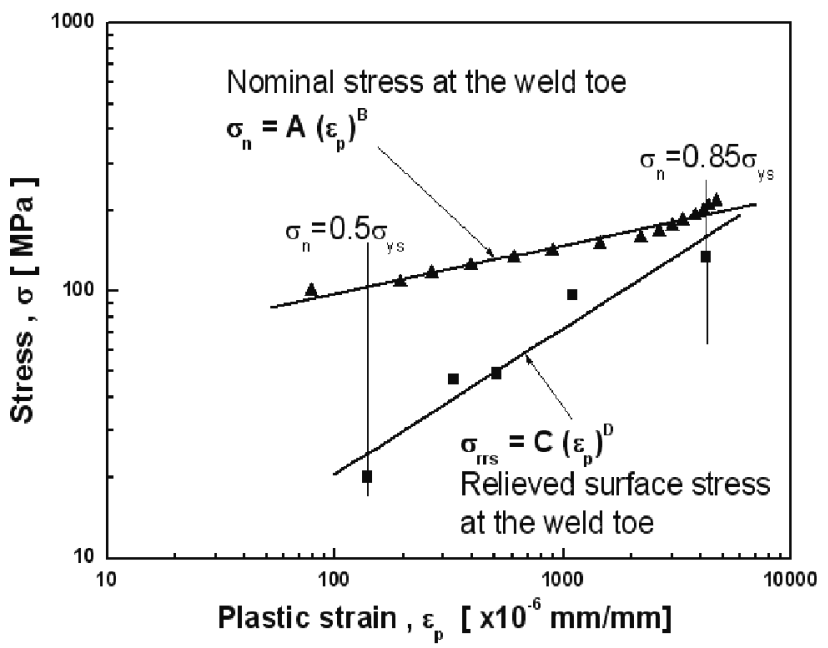

Fig. 11 The relations of measured plastic strain and relieved surface residual stress and nominal stress.

$$
\begin{aligned}
& \sigma_{u n n}=K_{w c} \cdot \sigma_{n} \\
& \sigma_{n}=A \cdot \varepsilon_{p}^{B} \\
& \sigma_{n}=C \cdot \varepsilon_{p}^{D}
\end{aligned}
$$

Eliminating plastic strains in Eq. (5) and (6) results in Eq. (7). A, B, C and D are experimental constants of $25.28 \mathrm{GPa}, 1.09$ $G P a, 0.25,0.61$ respectively.

$$
\sigma_{n}=\left[A \cdot C^{-\frac{-B}{D}}\right] \cdot \sigma_{r r s}^{\frac{B}{D}}
$$

Eq. (4), relating engineering stress $\left(\sigma_{n}\right)$ and unnotched engineering stress $\left(\sigma_{u n n}\right)$, can be generalized to Eq. (8) by using Eq. (6) and (7) to estimate the amount of released residual stress by engineering stress applied to the material. 


$$
\sigma_{u n n}=K_{w c} \times C_{w c} \times \sigma_{r r s} n_{w e}
$$

where, $n_{w c}=\frac{B}{D}$ and $C_{w c}=A \cdot C^{-\frac{B}{D}} n_{w c}=\frac{B}{D}, C_{w c}=A \cdot C^{-\frac{B}{D}}, \sigma_{u n n}$ is decided by material and weld stress concentration factor $\left(K_{w c}\right)$, material constant of weld $\left(C_{w c}\right)$ and weld strength constant $\left(n_{w c}\right)$ are experimental constants decided by weld shape and weld conditions. In case of gusset welding, test result is weld concentration factor $\left(K_{w c}\right)$ measured at weld toe.

\section{The change of fatigue life to overload}

The major parameters affecting the fatigue strength of welded structures are the overload and the resulting real stress status and residual stress at weld toe. The overload and the release of residual stress have the relation of Eq. (7). Therefore, in the fatigue test, the fatigue strength at any life can be described with the magnitude of overload. As shown in Fig. 12, for the fatigue life for $10^{5}$ cycles and $10^{6}$ cycles, the relation between the overload and fatigue strength can be defined as Eq. (9) and (10). The effect of overload to fatigue can be quantified by calculating predicted weld concentration factor $\left(K_{w c}\right)$ the status for each weld shape at weld toes where cracks initiate due to overload.

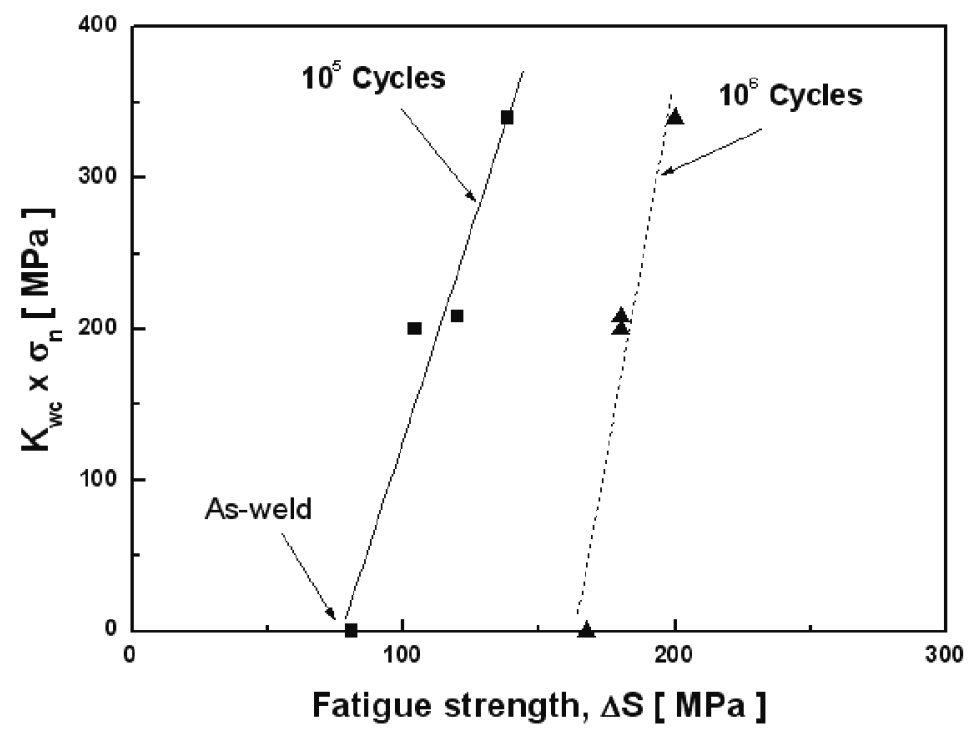

Fig. 12 Master curve for prediction of fatigue life.

The predicted fatigue strength of a gusset welded specimen is defined as Eq. (9) and (10) at $10^{5}$ cycles and $10^{6}$ cycles.

$$
\begin{aligned}
& \left(K_{w c} \times \sigma_{n}\right)=6.66 \times(\Delta S)-572.29 \\
& \left(K_{w c} \times \sigma_{n}\right)=27.76 \times(\Delta S)-1595.11
\end{aligned}
$$

Eq. (9) and Eq. (10) are experimental equations applicable only to gusset and could be generalized.

$$
\left(K_{w c} \times \sigma_{n}\right)=C_{f 1} \times(\Delta S)-C_{f 2}
$$

$C_{f 1}$ and $C_{f 2}$ are fatigue strength coefficients according to weld shape and weld conditions. 


\section{CONCLUSIONS}

Strains at weld toes are obtained to estimate residual stress and weld concentration factor which are dominating parameters of fatigue strength and life at gusset weld, a type of plank-frame. Accordingly studies are performed about their effect on fatigue strength and life and the following conclusions are obtained.

(1) The initial residual stress (As-weld) is the highest at weld toes and the tensile residual stress is decreased by the application of static overload. The amount of stress drop increases as the overload grows.

(2) The phenomenon becomes clearer as static overload gets higher for the same fatigue life.

(3) For fatigue life to mean stress, fatigue life decrease as mean stress increase in general. As mean stress gets higher, the amount of increase of fatigue strength falls. The amount of decrease of fatigue strength to mean stress is bigger in high cycle range.

(4) A linear relationship in double-logarithmic graph is found between local plastic strains and the magnitude of residual stress release at weld toes by static load. When overloads are applied to eliminate residual stress, the relation between the stress at weld toe and the released residual stress can be simplified to the following equation according to the change of mechanical properties and the material due to welding.

$$
\sigma_{u n n}=K_{w c} \times C_{w c} \times \sigma_{r r s} n_{w e}
$$

(5) Considering weld stress concentration factor, the fatigue strength at any life to overload can be generalized to the following equation.

$$
\left(K_{w c} \times \sigma_{n}\right)=C_{f 1} \times(\Delta S)-C_{f 2}
$$

\section{REFERENCES}

AWS., 1987. Welding Handbook, Volume 1. 8th ed. pp.231-233.

Bannantine, J.A., Comer, J.J. and Handrock, J.L., 1990. Fundamentals of Metal Fatigue Analysis. Prentice-Hall, Inc.

Gurney, T.R., 1979. Fatigue of Welded Structure. 2nd ed. Cambridge University Press.

Kim, H., 1992. A study on the fatigue crack opening behavior of the material with welding residual stress field. PhD. Korea University.

Kim, W.S., 1997. Residual Stress \& Fatigue strength in Welded Ship Structure. Journal of KWS, June, 15(3).

Kim, Y.S., 1989. The Welding Residual Stress and Occurrence of Welding Deformation Mechanism and its Countermeasures. Journal of KWS, Mar, 7(1).

Lee, Y.B. and Cho, N.I., 1995. Redistribution of Welding Residual Stress and its Effects on Fatigue Crack Propagation. Journal of KWS, Dec, 13(4).

Maddox, S.J., 1991. Fatigue Strength of Welded Structures. 2nd ed. Abington Publishing.

Park, J.S., Han, M.S. and Han, J.M., 1997. Mechanical Stress Relief Technology and its Application. Journal of KWS, 15(3). 